\title{
ARMAZENAMENTO DE SEMENTES DE IPÊ-BRANCO E IPÊ-ROXO EM DIFERENTES EMBALAGENS E AMBIENTES ${ }^{1}$
}

\author{
ALUISIO BRIGIDO BORBA FILHO², SONIA CRISTINA JULIANO GUALTIERI DE ANDRADE PEREZ ${ }^{3}$
}

\begin{abstract}
RESUMO - O armazenamento em condições ideais é de fundamental importância para a conservação da qualidade fisiológica de um lote de sementes. Nesse trabalho procurou-se identificar a condição adequada para o armazenamento de sementes de ipê-branco (Tabebuia roseo-alba (Ridl.) Sand.) e de ipê-roxo (Tabebuia impetiginosa (Mart.) Standl.), bem como avaliar métodos para estimar alterações na viabilidade e no vigor dessas sementes. Diferentes grupos de sementes foram acondicionados em saco de polietileno, saco de papel Kraft e lata e armazenados por até 300 dias em condições de laboratório, geladeira e câmara refrigerada. No início do armazenamento e a cada 60 dias, determinaram-se o teor de água, a porcentagem e a velocidade de germinação e a condutividade elétrica da solução de embebição das sementes. A melhor condição para conservação de sementes de T. roseo-alba e $T$. impetiginosa foi obtida com o acondicionamento em lata e manutenção em geladeira. Sementes de T. impetiginosa também podem ser conservadas embaladas em saco de polietileno, saco de papel ou lata quando estocadas em câmara refrigerada. Alterações no vigor de sementes dessas espécies são primeiramente identificadas pela redução da velocidade de germinação
\end{abstract}

Termos para indexação: Tabebuia, conservação de sementes, vigor.

\section{STORAGE OF IPÊ-BRANCO AND IPÊ-ROXO SEEDS IN DIFFERENT PACKAGINGS AND ENVIRONMENTS}

\begin{abstract}
Storage plays a crucial role in maintaining the physiological quality of a seed lot. In this study, we aimed to identify an adequate condition for storage of ipê-branco (Tabebuia roseo-alba (Ridl.) Sand.) and ipê-roxo (Tabebuia impetiginosa (Mart.) Standl.) seeds, and to evaluate methods to estimate changes in the viability and vigor of those seeds. Different groups of seeds were placed in polyethylene bags, Kraft paper bags and cans. The seeds were then stored for up to 300 days under laboratory, refrigerator, and refrigerated chamber conditions. Seed water content, percentage and speed germination and electric conductivity were determined at the start of storage and thereafter at every 60 days. The best $T$. roseo-alba and T. impetiginosa seed conservation condition was obtained with cans maintained in the refrigerator. T. impetiginosa seeds can also be kept in polyethylene bags, paper bags, or cans when stored in a refrigerated chamber. Seed vigor changes in these species are initially identified by decrease in the speed germination.
\end{abstract}

Index terms: Tabebuia, seed preservation, vigor.

\footnotetext{
${ }^{1}$ Submetido em 22/05/2007. Aceito para publicação em 14/11/2007. Parte da Tese de Doutorado do primeiro autor apresentada ao Programa de PósGraduação em Ecologia e Recursos Naturais da Universidade Federal de São Carlos (PPG/ERN-UFSCar);

${ }^{2}$ Eng. Agr., Dr., Professor Adjunto, Departamento de Fitotecnia e
}

Fitossanidade, Universidade Federal de Mato Grosso, borbafilho@terra. com.br;

${ }^{3}$ Bióloga, Dr., Professora Titular, Departamento de Botânica, Universidade Federal de São Carlos, dscp@power.ufscar.br. 


\section{INTRODUÇÃO}

O ipê-branco (Tabebuia roseo-alba (Ridl.) Sand.) e o ipê-roxo (Tabebuia impetiginosa (Mart.) Standl.) pertencem à família Bignoniaceae que ocorrem em várias regiões do Brasil. Apresentam grande valor madeireiro, medicinal e ornamental, com ampla utilização na arborização urbana e na recomposição vegetal de áreas degradadas (Pott e Pott, 1994; Lorenzi, 2000) . Essas espécies produzem sementes aladas em grande quantidade com curto período de viabilidade em condições naturais (Piña-Rodrigues e Piratelli, 1993; Lorenzi, 2000).

Essa perda de viabilidade é decorrente do processo de deterioração, que tem início logo após a maturidade fisiológica, mas somente influencia a viabilidade quando o processo progride para um estádio avançado, porque pequenos danos são reversíveis e possíveis de serem reparados pelas sementes (Schmidt, 2000).

As espécies florestais apresentam, em geral, uma produção irregular de sementes, sendo abundante em um ano e escassa em outros (Aguiar, 1995). Por essa razão, depois de colhidas e até serem utilizadas para semeadura, as sementes devem ser armazenadas de maneira a atrasar ao máximo o processo de deterioração. Esse procedimento é de particular importância para as sementes com curto período de viabilidade (Carneiro e Aguiar, 1993).

Em sementes armazenadas sob condições adequadas, a velocidade do processo de deterioração pode ser diminuída, permitindo a conservação da viabilidade das mesmas por período mais prolongado do que o obtido em condições naturais (Figliolia e Piña-Rodrigues, 1995). A umidade relativa do ar e a temperatura do ambiente de armazenamento são os principais fatores que afetam a qualidade das sementes durante o armazenamento. Condições de elevada umidade relativa do ar podem proporcionar o reinício das atividades metabólicas do embrião, enquanto que temperaturas elevadas ocasionam aumento da atividade respiratória e esgotamento das substâncias de reserva acumuladas (Aguiar, 1995), assim como, tais condições podem favorecer a ação de fungos e insetos, os quais aceleram a deterioração das sementes (Carvalho e Nakagawa, 2000).

A conservação da qualidade fisiológica das sementes está também relacionada ao tipo de embalagem utilizada, conforme a maior ou menor facilidade que apresentam para as trocas de vapor d'água entre as sementes e a atmosfera do ambiente em que estão armazenadas (Marcos Filho, 2005).
As sementes de espécies do gênero Tabebuia são consideradas ortodoxas quanto ao comportamento fisiológico que apresentam durante o armazenamento (Mello e Eira, 1995; Silva et al., 2001; Gemaque et al., 2005). Sementes com esse comportamento, caracterizado por Roberts (1973), são tolerantes à dessecação e podem ser armazenadas com reduzido teor de água em ambientes com baixos valores de temperatura e umidade relativa do ar. A habilidade das células de sementes ortodoxas sobreviverem à dessecação envolve a síntese de proteínas conhecidas como LEA (late embryogenic abundant), produzidas na embriogênese tardia, o acúmulo de açúcares solúveis e a presença de antioxidantes, que permitem que o citoplasma atinja o chamado estado vítreo (Berjak, 2006).

Comprovando esse fato, Kageyama et al. (1992) verificaram que sementes de Tabebuia heptaphylla acondicionadas em sacos de plástico ou de papel e armazenadas em câmara fria e seca ou câmara seca, mantiveram a germinação ao redor de $65 \%$ após 15 meses de armazenamento. Cabral et al. (2003) verificaram que sementes de Tabebuia aurea acondicionadas em sacos de papel Kraft, de algodão ou de plástico transparente permeável, em câmara fria e seca, mantiveram porcentagem de germinação variando de $88 \%$ a $97 \%$ durante 120 dias.

Entretanto, o potencial fisiológico das sementes avaliadas nesses estudos foi determinado com o uso de características derivadas do teste de germinação. Testes baseados na integridade do sistema de membranas celulares estimam o vigor das sementes e permitem que a deterioração seja detectada em sua fase inicial (Marcos Filho, 1999). O teste de condutividade elétrica, nesse sentido, relaciona a quantidade de substâncias liberada pelas sementes durante a embebição com a integridade das membranas, uma vez que membranas mal estruturadas, desorganizadas e danificadas estão associadas à redução do vigor das sementes (Vieira e Krzyzanowski, 1999).

Nesse trabalho procurou-se identificar a condição adequada para o armazenamento de sementes de ipêbranco (Tabebuia roseo-alba) e de ipê-roxo (Tabebuia impetiginosa), bem como avaliar métodos para estimar alterações na viabilidade e no vigor dessas sementes.

\section{MATERIAL E MÉTODOS}

Os trabalhos foram conduzidos no Laboratório de 
Sementes da Faculdade de Agronomia e Medicina Veterinária da Universidade Federal de Mato Grosso. Foram utilizadas sementes certificadas de Tabebuia roseo-alba provenientes da Fundação para Conservação e a Produção Florestal do Estado de São Paulo, coletadas no município de Araraquara -

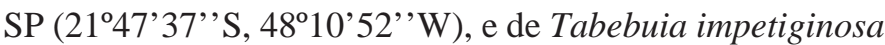
provenientes do Instituto de Pesquisas e Estudos Florestais, coletadas no município de Rio das Pedras - SP (22050'27' 'S, 47³6’36' $\mathrm{W}$ ).

Após triagem manual para garantir homogeneidade de tamanho e de coloração, bem como melhor estado de conservação, as sementes de cada espécie foram acondicionadas em embalagens individuais, constituídas de diferentes materiais: saco de polietileno de baixa densidade, transparente, com 0,06mm de espessura, saco de papel Kraft natural, com $40 \mathrm{~g} / \mathrm{m}^{2}$ e lata de folha-de-flandres com tampa, com capacidade para $850 \mathrm{~mL}$. Em cada embalagem foi colocada quantidade de sementes necessária para a realização dos testes de cada avaliação posterior.

Assim acondicionadas, as sementes foram armazenadas por até 300 dias em três ambientes: em laboratório, sem controle de condições ambientais $\left(21\right.$ a $31^{\circ} \mathrm{C}$; 40 a $78 \%$ de umidade relativa), em geladeira $\left(4\right.$ a $6^{\circ} \mathrm{C}$; 38 a $43 \%$ de umidade relativa) e em câmara refrigerada $\left(14\right.$ a $20^{\circ} \mathrm{C}$; 74 a $82 \%$ de umidade relativa), obtida com uso de um condicionador de ar e de um desumidificador. No início do armazenamento e após cada período de 60 dias, determinou-se o teor de água e foram realizados os testes de germinação e de condutividade elétrica da solução de embebição das sementes mantidas nas diferentes condições de embalagem e ambiente. As sementes analisadas no início do armazenamento foram consideradas como grupo controle.

O teor de água foi determinado pelo método de estufa a $105 \pm 3^{\circ} \mathrm{C}$ durante 24 horas, conforme as Regras para Análise de Sementes (Brasil, 1992), utilizando-se duas amostras de sementes intactas de aproximadamente $1,0 \mathrm{~g}$ para $T$. roseoalba e de 4,0 a 5,0g para $T$. impetiginosa.

Os testes de germinação foram realizados em caixas de plástico transparente (gerbox) com seis repetições de 15 sementes, utilizando-se como substrato papel mata-borrão umedecido com água destilada, na forma entre-papel para $T$. roseo-alba e na forma sobre-papel para T. impetiginosa (Borba Filho e Perez, 2003). Após a distribuição das sementes nos substratos, as caixas foram envolvidas com filme de policloreto de vinila (PVC) transparente, tampadas e mantidas em câmara de germinação à temperatura constante de $27^{\circ} \mathrm{C}$ (Borges e Rena, 1993) e fotoperíodo de oito horas (Degan et al., 1997). Foram realizadas contagens diárias, considerandose germinadas as sementes com protrusão de raiz primária igual ou superior a 2,0mm e curvatura geotrópica positiva (Labouriau, 1983). A partir desses dados foram calculados os valores de porcentagem e velocidade média de germinação (Borghetti e Ferreira, 2004).

Os testes de condutividade elétrica da solução de embebição das sementes foram realizados pelo sistema de massa (Vieira e Krzyzanowski, 1999), com seis repetições de 15 sementes intactas, previamente pesadas em balança de precisão. As sementes foram colocadas em copos de plástico com capacidade para $200 \mathrm{~mL}$, nos quais foram adicionados $75 \mathrm{~mL}$ de água deionizada. Os copos contendo as sementes e a água foram colocados em câmara de germinação (tipo $\mathrm{BOD})$ a $25^{\circ} \mathrm{C}$ durante 24 horas, sendo então efetuadas as leituras de condutividade elétrica da solução de embebição das sementes e os resultados expressos em $\mu \mathrm{S} . \mathrm{cm}^{-1} \cdot \mathrm{g}^{-1}$.

Utilizou-se delineamento inteiramente casualizado, com seis repetições, em esquema fatorial $(3 \times 3 \times 5)+1$, sendo três embalagens, três ambientes, cinco períodos de armazenamento e o grupo controle. Os valores das variáveis dependentes atenderam aos pressupostos de normalidade dos resíduos e homogeneidade de variâncias, sendo analisados sem transformação. Os dados obtidos foram submetidos à análise de variância pelo teste F. Para identificar alterações na qualidade fisiológica das sementes durante $\mathrm{o}$ armazenamento, as médias dos tratamentos foram comparadas com os valores obtidos no início (grupo controle) pelo teste de Dunnett a $5 \%$, e para verificar a condição mais adequada para o armazenamento das sementes, as médias foram comparadas entre si pelo teste de Tukey a 5\% (Banzatto e Kronka, 1992). Para essas análises foram utilizados os programas SPSS 12.0 e Sisvar 4.3, respectivamente. Para cada espécie foram calculados os coeficientes de correlação simples de Pearson para as combinações entre os resultados obtidos nos testes de condutividade elétrica e os resultados de porcentagem e de velocidade de germinação.

\section{RESULTADOS E DISCUSSÃO}

Os resultados obtidos para as variáveis teor de água, porcentagem de germinação, velocidade de germinação e condutividade elétrica, determinados nas sementes no início do armazenamento, encontram-se na Tabela 1. Esses dados são referentes ao grupo controle de cada uma das espécies em estudo. 
TABELA 1. Valores médios de teor de água (TA), porcen-tagem (G) e velocidade de germinação (V) e condutividade elétrica (CE) das sementes de Tabebuia roseo-alba e Tabebuia impetiginosa, no início do armazenamento.

\begin{tabular}{ccccc}
\hline \multicolumn{1}{c}{ Espécie } & TA & $\mathrm{G}$ & $\mathrm{V}$ & $\mathrm{CE}$ \\
& $(\%)$ & $(\%)$ & $\left(\mathrm{dias}^{-1}\right)$ & $\left(\mu \mathrm{S} \cdot \mathrm{cm}^{-1} \cdot \mathrm{g}^{-1}\right)$ \\
Tabebuia roseo-alba & 7,9 & 91 & 0,438 & 14,76 \\
Tabebuia impetiginosa & 8,3 & 87 & 0,220 & 246,63 \\
\hline
\end{tabular}

Os valores médios de teor de água nas sementes verificados durante o período de armazenamento são apresentados na Tabela 2, com valores iniciais de 7,9\% para T. roseo-alba e de $8,3 \%$ para T. impetiginosa. Alguns dos valores de teor de água foram superiores ao do respectivo grupo controle, porém, todos estão situados abaixo de 9\%, limite considerado como possível para o armazenamento de sementes de espécies do gênero Tabebuia (Mello e Eira, 1995).

TABELA 2. Valores médios de teor de água (\%) de sementes de Tabebuia roseo-alba e Tabebuia impetiginosa mantidas sob diferentes condições de armazenamento.

\begin{tabular}{|c|c|c|c|c|c|c|c|}
\hline \multirow{3}{*}{$\begin{array}{l}\text { Armazenamento } \\
\text { (dias) }\end{array}$} & \multirow{3}{*}{ Embalagem } & \multicolumn{3}{|c|}{ Tabebuia roseo-alba } & \multicolumn{3}{|c|}{ Tabebuia impetiginosa } \\
\hline & & \multicolumn{3}{|c|}{ Ambiente } & \multicolumn{3}{|c|}{ Ambiente } \\
\hline & & Laboratório & Geladeira & Câmara & Laboratório & Geladeira & Câmara \\
\hline & & \multicolumn{3}{|c|}{ Controle $=7,9 \%$} & \multicolumn{3}{|c|}{ Controle $=8,3 \%$} \\
\hline \multirow{3}{*}{60} & Polietileno & $8,5(*)$ & 7,8 & 7,9 & 8,1 & 7,5 & 7,8 \\
\hline & Papel & 8,1 & 7,1 & 7,8 & 8,6 & 6,8 & 8,3 \\
\hline & Lata & 8,1 & 7,3 & 7,4 & 7,9 & 7,7 & 8,0 \\
\hline \multirow{3}{*}{120} & Polietileno & $8,6(*)$ & 7,2 & $8,6(*)$ & 8,7 & 7,9 & 8,2 \\
\hline & Papel & 8,3 & 6,6 & 7,7 & 8,0 & 7,5 & 8,3 \\
\hline & Lata & $8,5(*)$ & 7,8 & 7,6 & $8,9(*)$ & 7,7 & 8,3 \\
\hline \multirow{3}{*}{180} & Polietileno & 6,5 & 6,5 & 7,2 & 8,1 & 6,9 & 8,0 \\
\hline & Papel & 6,6 & 6,6 & 7,7 & 7,4 & 6,4 & 8,2 \\
\hline & Lata & 6,4 & 7,0 & 7,0 & 7,8 & 6,9 & 8,1 \\
\hline \multirow{3}{*}{240} & Polietileno & 6,5 & 6,5 & 7,0 & 7,4 & 7,2 & 8,0 \\
\hline & Papel & 6,2 & 5,9 & 7,1 & 8,1 & 6,8 & 8,2 \\
\hline & Lata & 6,3 & 6,7 & 6,9 & 8,0 & 7,4 & 8,2 \\
\hline \multirow{3}{*}{300} & Polietileno & 7,7 & 6,7 & 7,6 & $8,8(*)$ & 7,2 & 8,3 \\
\hline & Papel & 7,4 & 6,7 & 8,0 & 8,3 & 6,9 & $8,8(*)$ \\
\hline & Lata & 7,9 & 6,8 & 7,4 & $8,8(*)$ & 7,4 & 8,6 \\
\hline
\end{tabular}

$\left(^{*}\right)$ - diferença significativa em relação ao tratamento controle pelo teste unilateral de Dunnett a 5 \% de probabilidade.

No início do armazenamento, a germinação das sementes foi de $91 \%$ para $T$. roseo-alba e de $87 \%$ para $T$. impetiginosa. As sementes das duas espécies, acondicionadas em qualquer das embalagens e armazenadas em ambiente de laboratório, apresentaram significativa redução nos valores de porcentagem de germinação no momento da primeira 
avaliação. A partir de 120 dias de armazenamento observouse perda de viabilidade das sementes mantidas nesse ambiente (Tabela 3). Resultado semelhante foi obtido por Souza et al. (2005), os quais verificaram que sementes de Tabebuia serratifolia armazenadas em ambiente de laboratório (27 \pm $3^{\circ} \mathrm{C}$ e $62 \pm 2 \%$ UR) apresentaram perda total de vigor aos 120 dias de armazenamento.

TABELA 3. Valores médios de porcentagem de germinação de sementes de Tabebuia roseo-alba e Tabebuia impetiginosa mantidas sob diferentes condições de armazenamento.

\begin{tabular}{|c|c|c|c|c|c|c|c|}
\hline \multirow{3}{*}{$\begin{array}{l}\text { Armazenamento } \\
\text { (dias) }\end{array}$} & \multirow{3}{*}{ Embalagem } & \multicolumn{3}{|c|}{ Tabebuia roseo-alba } & \multicolumn{3}{|c|}{ Tabebuia impetiginosa } \\
\hline & & \multicolumn{3}{|c|}{ Ambiente } & \multicolumn{3}{|c|}{ Ambiente } \\
\hline & & Laboratório & Geladeira & Câmara & Laboratório & Geladeira & Câmara \\
\hline & & \multicolumn{6}{|c|}{ Germinação (\%) } \\
\hline & & \multicolumn{3}{|c|}{ Controle $=91 \%$} & \multicolumn{3}{|c|}{ Controle $=87 \%$} \\
\hline \multirow{3}{*}{60} & Polietileno & $28(*)$ & 81 & 83 & $23(*)$ & 81 & 83 \\
\hline & Papel & $37(*)$ & 92 & 92 & $7(*)$ & 84 & 79 \\
\hline & Lata & $40(*)$ & 90 & 89 & $64(*)$ & 84 & 83 \\
\hline \multirow{3}{*}{120} & Polietileno & $0(*)$ & 78 & 83 & $0(*)$ & 78 & 77 \\
\hline & Papel & $0(*)$ & 94 & 89 & $0(*)$ & 74 & 90 \\
\hline & Lata & $0(*)$ & 90 & 92 & $2(*)$ & 82 & 84 \\
\hline \multirow{3}{*}{180} & Polietileno & $0(*)$ & 82 & 80 & $0(*)$ & $73(*)$ & 74 \\
\hline & Papel & $0(*)$ & 83 & 83 & $0(*)$ & $72(*)$ & 78 \\
\hline & Lata & $0(*)$ & 84 & 83 & $0(*)$ & 84 & 89 \\
\hline \multirow{3}{*}{240} & Polietileno & $0(*)$ & 82 & $75(*)$ & $0(*)$ & 79 & 87 \\
\hline & Papel & $0(*)$ & 90 & 87 & $0(*)$ & 84 & 85 \\
\hline & Lata & $0(*)$ & 95 & 81 & $0(*)$ & 88 & 79 \\
\hline \multirow{3}{*}{300} & Polietileno & $0(*)$ & 89 & 81 & $0(*)$ & 79 & 83 \\
\hline & Papel & $0(*)$ & 83 & 90 & $0(*)$ & 84 & 74 \\
\hline & Lata & $0(*)$ & 88 & 82 & $0(*)$ & 84 & 84 \\
\hline
\end{tabular}

(*) - diferença significativa em relação ao tratamento controle pelo teste unilateral de Dunnett a 5\% de probabilidade.

Uma vez que os valores de teor de água não atingiram limites prejudiciais à qualidade fisiológica das sementes, a perda de viabilidade dessas quando mantidas em laboratório, está relacionada às temperaturas registradas nesse ambiente, que variaram de 21 a $31^{\circ} \mathrm{C}$. Essa situação causa aumento da atividade respiratória das sementes e a conseqüente redução da qualidade fisiológica das mesmas (Marcos Filho, 2005).

Durante o período de armazenamento, as sementes de $T$. roseo-alba acondicionadas em qualquer uma das embalagens e mantidas em ambiente de geladeira não apresentaram redução da porcentagem de germinação. Em câmara refrigerada observou-se redução significativa apenas aos 240 dias de armazenamento em sementes embaladas em saco de polietileno (Tabela 3).

Nas sementes de T. impetiginosa mantidas em geladeira, observou-se redução da porcentagem de germinação somente aos 180 dias de armazenamento para aquelas embaladas em sacos de polietileno ou de papel. Quando conservadas em câmara refrigerada, as sementes dessa espécie mantiveram a viabilidade nas diferentes condições de embalagens e 
períodos de armazenamento (Tabela 3).

As reduções observadas na porcentagem de germinação das sementes em avaliações intermediárias durante o período de armazenamento foram causadas por fatores alheios aos tratamentos, uma vez que não se repetiram nas avaliações posteriores. Desse modo, as sementes de T. roseo-alba e de $T$. impetiginosa, independente da embalagem de acondicionamento e mantidas em ambiente de geladeira ou câmara refrigerada, conservaram a capacidade germinativa aos 300 dias de armazenamento. Resultados corroborando a conservação da capacidade germinativa de sementes de espécies do gênero Tabebuia, quando armazenadas em ambientes com baixa temperatura, foram obtidos com $T$. heptaphylla em câmara fria e seca e câmara seca (Kageyama et al., 1992), com T. heterophylla em câmara fria (Silva et al., 2001) e com T. aurea em câmara fria e seca (Cabral et al., 2003).

Quanto ao vigor das sementes, avaliado pela velocidade de germinação, os valores obtidos antes do armazenamento foram de 0,438 dias $^{-1}$ para $T$. roseo-alba e de 0,220 dias $^{-1}$ para T. impetiginosa.

Em ambiente de geladeira, observou-se decréscimo do vigor de sementes de T. roseo-alba acondicionadas em saco de polietileno ou de papel após 120 dias de armazenamento, bem como após 180 dias, quando embaladas em saco de papel. Além disto, também se observou redução do vigor aos 300 dias de armazenamento em sementes mantidas em embalagens de polietileno, papel ou lata (Tabela 4).

TABELA 4. Valores médios de velocidade de germinação $\left(\right.$ dias $\left.^{-1}\right)$ de sementes de Tabebuia roseo-alba e Tabebuia impetiginosa mantidas sob diferentes condições de armazenamento.

\begin{tabular}{|c|c|c|c|c|c|c|c|}
\hline \multirow{3}{*}{$\begin{array}{l}\text { Armazenamento } \\
\text { (dias) }\end{array}$} & \multirow{3}{*}{ Embalagem } & \multicolumn{3}{|c|}{ Tabebuia roseo-alba } & \multicolumn{3}{|c|}{ Tabebuia impetiginosa } \\
\hline & & \multicolumn{3}{|c|}{ Ambiente } & \multicolumn{3}{|c|}{ Ambiente } \\
\hline & & Laboratório & Geladeira & Câmara & Laboratório & Geladeira & Câmara \\
\hline & & \multicolumn{6}{|c|}{ Velocidade de germinação $\left(\right.$ dias $\left.^{-1}\right)$} \\
\hline & & \multicolumn{3}{|c|}{ Controle $=0,438$ dias $^{-1}$} & \multicolumn{3}{|c|}{ Controle $=0,220$ dias $^{-1}$} \\
\hline \multirow{3}{*}{60} & Polietileno & $0,335(*)$ & 0,409 & $0,360(*)$ & 0,194 & 0,239 & 0,218 \\
\hline & Papel & $0,295(*)$ & 0,399 & $0,375(*)$ & $0,130(*)$ & 0,227 & 0,282 \\
\hline & Lata & $0,300(*)$ & 0,423 & 0,417 & 0,231 & 0,233 & 0,264 \\
\hline \multirow{3}{*}{120} & Polietileno & $0,00(*)$ & $0,353(*)$ & 0,403 & $0,00(*)$ & 0,215 & 0,229 \\
\hline & Papel & $0,00(*)$ & $0,358(*)$ & 0,423 & $0,00(*)$ & 0,223 & 0,212 \\
\hline & Lata & $0,00(*)$ & 0,418 & $0,376(*)$ & $0,125(*)$ & 0,238 & 0,217 \\
\hline \multirow{3}{*}{180} & Polietileno & $0,00(*)$ & 0,408 & $0,375(*)$ & $0,00(*)$ & 0,235 & 0,211 \\
\hline & Papel & $0,00(*)$ & $0,375(*)$ & $0,375(*)$ & $0,00(*)$ & 0,226 & 0,227 \\
\hline & Lata & $0,00(*)$ & 0,412 & $0,386(*)$ & $0,00(*)$ & 0,239 & 0,237 \\
\hline \multirow{3}{*}{240} & Polietileno & $0,00(*)$ & 0,425 & $0,369(*)$ & $0,00(*)$ & 0,217 & 0,233 \\
\hline & Papel & $0,00(*)$ & 0,412 & $0,385(*)$ & $0,00(*)$ & 0,219 & 0,243 \\
\hline & Lata & $0,00(*)$ & 0,425 & 0,400 & $0,00(*)$ & 0,232 & 0,246 \\
\hline \multirow{3}{*}{300} & Polietileno & $0,00(*)$ & $0,352(*)$ & $0,314(*)$ & $0,00(*)$ & 0,217 & 0,217 \\
\hline & Papel & $0,00(*)$ & $0,377(*)$ & $0,341(*)$ & $0,00(*)$ & 0,237 & 0,215 \\
\hline & Lata & $0,00(*)$ & $0,387(*)$ & $0,351(*)$ & $0,00(*)$ & 0,224 & 0,216 \\
\hline
\end{tabular}

$(*)$ - diferença significativa em relação ao tratamento controle pelo teste unilateral de Dunnett a 5\% de probabilidade. 
Quando mantidas em ambiente de câmara refrigerada, as sementes de T. roseo-alba apresentaram redução mais destacada da velocidade de germinação, verificada aos 60 dias de armazenamento quando embaladas em saco de polietileno e saco de papel e a partir de 120 dias, em sementes acondicionadas em lata. Desse modo, para essa espécie, o vigor manteve-se inalterado apenas nas sementes embaladas em lata e conservadas em geladeira por até 240 dias. Em contraste, as sementes de T. impetiginosa, independente da embalagem utilizada e mantidas nos ambientes de geladeira ou câmara refrigerada, conservaram o vigor até 300 dias de armazenamento (Tabela 4).

Com relação ao vigor avaliado pelo teste de condutividade elétrica, foram registrados no início do armazenamento valores de $14,76 \mu \mathrm{S} . \mathrm{cm}^{-1} . \mathrm{g}^{-1}$ para T. roseo-alba e de $246,63 \mu \mathrm{S}$. $\mathrm{cm}^{-1} \cdot \mathrm{g}^{-1}$ para T. impetiginosa. As sementes de T. roseo-alba estocadas em laboratório apresentaram elevados valores dessa característica em virtude da deterioração e conseqüente perda da capacidade germinativa, manifestada a partir dos 60 dias de armazenamento (Tabela 5). Independente da embalagem de acondicionamento, os valores de condutividade elétrica das sementes de $T$. roseo-alba, mantidas em geladeira ou câmara refrigerada, não foram superiores ao do grupo controle, indicando que não houve alteração do vigor durante o armazenamento. Entretanto, esses resultados não refletem a redução do vigor detectada pelo teste de velocidade de germinação aplicado às sementes armazenadas nesses ambientes.

TABELA 5. Valores médios de condutividade elétrica $\left(\mu \mathrm{S} . \mathrm{cm}^{-1} \cdot \mathrm{g}^{-1}\right)$ de sementes de Tabebuia roseo-alba e Tabebuia impetiginosa mantidas sob diferentes condições de armazenamento.

\begin{tabular}{|c|c|c|c|c|c|c|c|}
\hline \multirow{3}{*}{$\begin{array}{l}\text { Armazenamento } \\
\qquad \text { (dias) }\end{array}$} & \multirow{3}{*}{ Embalagem } & \multicolumn{3}{|c|}{ Tabebuia roseo-alba } & \multicolumn{3}{|c|}{ Tabebuia impetiginosa } \\
\hline & & \multicolumn{3}{|c|}{ Ambiente } & \multicolumn{3}{|c|}{ Ambiente } \\
\hline & & Laboratório & Geladeira & $\overline{\text { Câmara }}$ & Laboratório & Geladeira & Câmara \\
\hline & & \multicolumn{3}{|c|}{ Controle $=14,76 \mu \mathrm{S} \cdot \mathrm{cm}^{-1} \cdot \mathrm{g}^{-1}$} & \multicolumn{3}{|c|}{ Controle $=246,63 \mu \mathrm{S} \cdot \mathrm{cm}^{-1} \cdot \mathrm{g}^{-1}$} \\
\hline \multirow{3}{*}{60} & Polietileno & $55,43(*)$ & 25,37 & 27,18 & 270,31 & 277,93 & 185,16 \\
\hline & Papel & $46,08(*)$ & 25,27 & 17,04 & 283,12 & 240,91 & 174,87 \\
\hline & Lata & $34,31(*)$ & 24,13 & 16,39 & 268,34 & 267,43 & 197,06 \\
\hline \multirow{3}{*}{120} & Polietileno & $115,37(*)$ & 21,96 & 25,17 & 271,54 & 226,98 & 190,32 \\
\hline & Papel & $113,43(*)$ & 20,80 & 23,85 & 273,08 & 193,37 & 164,69 \\
\hline & Lata & $111,46(*)$ & 19,61 & 21,30 & 267,12 & 173,37 & 209,67 \\
\hline \multirow{3}{*}{180} & Polietileno & $95,94(*)$ & 16,62 & 20,33 & 281,41 & 255,99 & 183,77 \\
\hline & Papel & $106,05(*)$ & 19,50 & 20,25 & 282,77 & 253,61 & 164,69 \\
\hline & Lata & $85,71(*)$ & 19,98 & 13,83 & $329,45(*)$ & 264,33 & 201,23 \\
\hline \multirow{3}{*}{240} & Polietileno & $110,61\left(^{*}\right)$ & 19,54 & 22,05 & $293,16(*)$ & 247,83 & 169,71 \\
\hline & Papel & $101,07(*)$ & 18,97 & 17,57 & $320,12(*)$ & 218,09 & 164,38 \\
\hline & Lata & $106,51(*)$ & 18,30 & 18,30 & $296,59(*)$ & 156,11 & 184,79 \\
\hline \multirow{3}{*}{300} & Polietileno & $104,50(*)$ & 25,23 & 28,76 & $312,42(*)$ & 240,42 & 224,51 \\
\hline & Papel & $101,21(*)$ & 19,40 & 17,99 & $321,79(*)$ & 211,49 & 222,58 \\
\hline & Lata & $93,24(*)$ & 22,43 & 12,97 & $284,37\left(^{*}\right)$ & 220,13 & 235,84 \\
\hline
\end{tabular}

(*) - diferença significativa em relação ao tratamento controle pelo teste unilateral de Dunnett a $5 \%$ de probabilidade.

Quanto às sementes de T. impetiginosa mantidas em laboratório, somente foram observados valores de condutividade elétrica superiores ao do grupo controle aos 180 dias de armazenamento nas sementes acondicionadas em 
lata, e em todas as embalagens nos períodos subseqüentes. Esses resultados também não estão de acordo com o registrado pelo teste de velocidade de germinação nos períodos iniciais de armazenamento dessas sementes em laboratório. Nos ambientes de geladeira ou câmara refrigerada, os valores médios de condutividade elétrica das sementes de $T$. impetiginosa acondicionadas nas embalagens de polietileno, papel ou lata, não apresentaram valores superiores ao do grupo controle (Tabela 5).

Uma vez que em ambiente de laboratório não ocorreu germinação das sementes das duas espécies após 60 dias de armazenamento, foram considerados para os cálculos dos coeficientes de correlação simples, somente os resultados obtidos nos testes de condutividade elétrica e de porcentagem e velocidade de germinação das sementes armazenadas em geladeira e câmara refrigerada. Observou-se que os valores dos coeficientes de correlação foram inferiores a $\pm 0,40$ (Tabela 6), significando baixa ou muito baixa relação entre as variáveis (Bisquerra et al., 2004).

A análise desses resultados indica que o teste de condutividade elétrica, nas condições em que foi realizado no presente trabalho, não foi sensível para detectar variações no vigor das sementes de $T$. roseo-alba e T. impetiginosa. Os resultados desse teste podem ser afetados por fatores como características da semente, qualidade e volume de água, temperatura e duração do período de embebição e número de sementes testadas (Vieira e Krzyzanowski, 1999; Marchi e Cícero, 2002).

TABELA 6. Coeficientes de correlação simples entre os valores obtidos nos testes de condutividade elétrica (CE) e de porcentagem (G) e velocidade de germinação (V) de sementes de Tabebuia roseo-alba e Tabebuia impetiginosa mantidas sob diferentes condições de armazenamento.

\begin{tabular}{|c|c|c|c|c|c|c|c|c|}
\hline \multirow{4}{*}{ Embalagem } & \multicolumn{4}{|c|}{ Tabebuia roseo-alba } & \multicolumn{4}{|c|}{ Tabebuia impetiginosa } \\
\hline & \multicolumn{4}{|c|}{ Ambiente } & \multicolumn{4}{|c|}{ Ambiente } \\
\hline & \multicolumn{2}{|c|}{ Geladeira } & \multicolumn{2}{|c|}{ Câmara } & \multicolumn{2}{|c|}{ Geladeira } & \multicolumn{2}{|c|}{ Câmara } \\
\hline & $\mathrm{CE} \times \mathrm{G}$ & CE x V & CE x G & CE x V & $\mathrm{CE} \times \mathrm{G}$ & CE x V & $\mathrm{CE} \times \mathrm{G}$ & $\mathrm{CE} \times \mathrm{V}$ \\
\hline Polietileno & 0,126 & $-0,002$ & $-0,291$ & $-0,007$ & $-0,087$ & 0,395 & $-0,047$ & $-0,075$ \\
\hline Papel & $-0,007$ & 0,074 & $-0,157$ & 0,034 & $-0,188$ & 0,274 & $-0,215$ & $-0,111$ \\
\hline Lata & 0,040 & 0,070 & 0,227 & $-0,001$ & $-0,112$ & 0,033 & $-0,100$ & $-0,196$ \\
\hline
\end{tabular}

O valor da condutividade elétrica é determinado em função da quantidade de lixiviados presentes na solução de embebição das sementes, relacionando o vigor à integridade do sistema de membranas celulares (Vieira e Krzyzanowski, 1999). Os trabalhos realizados em laboratório que incluem o teste de condutividade elétrica para avaliação do vigor de sementes florestais são ainda reduzidos. Para Barbedo e Cícero (1998), os resultados do teste de condutividade elétrica permitiram a separação de lotes de sementes de Inga uruguensis (ingá). Por sua vez, Marques et al. (2002) verificaram eficiência desse teste para diferenciar lotes de sementes de Dalbergia nigra (jacarandá-da-bahia), com alto grau de associação com o teste de germinação, e Santos e Paula (2005) consideraram o teste de condutividade elétrica promissor para diferenciar lotes de sementes de Sebastiania commersoniana (branquilho).

Por meio da comparação das médias sugerida pela análise de variância do modelo fatorial, foi possível determinar as melhores condições de embalagem e ambiente para manutenção do potencial fisiológico das sementes durante o armazenamento (Tabela 7). Em sementes de T. roseoalba a interação entre os fatores embalagem e ambiente não apresentou efeito significativo para porcentagem de germinação, porém foi significativa para velocidade de germinação. Em sementes de T. impetiginosa observou-se efeito significativo da interação entre esses fatores, tanto para porcentagem quanto para velocidade de germinação.

Desse modo, verificou-se que a melhor condição para o armazenamento de sementes de T. roseo-alba foi obtida com o acondicionamento em lata e manutenção em geladeira. As sementes de $T$. impetiginosa apresentaram melhor qualidade fisiológica com o acondicionamento em lata quando armazenadas em geladeira, porém, não houve diferença entre as embalagens quando estocadas em câmara refrigerada. 
TABELA 7. Interação entre os fatores embalagem e ambiente para os valores de porcentagem e velocidade de germinação obtidos com sementes de Tabebuia roseo-alba e Tabebuia impetiginosa submetidas a diferentes condições de armazenamento.

\begin{tabular}{|c|c|c|c|c|}
\hline \multirow{2}{*}{ Embalagem } & \multicolumn{3}{|c|}{ Ambiente } & \multirow[b]{2}{*}{ Média } \\
\hline & Laboratório & Geladeira & Câmara & \\
\hline \multicolumn{5}{|c|}{ Tabebuia roseo-alba } \\
\hline \multicolumn{5}{|c|}{ Germinação (\%) } \\
\hline Polietileno & 6 & 82 & 81 & $56 \mathrm{~B}$ \\
\hline Papel & 7 & 90 & 88 & $62 \mathrm{~A}$ \\
\hline Lata & 8 & 90 & 86 & $61 \mathrm{~A}$ \\
\hline Média & $7 \mathrm{~b}$ & $87 \mathrm{a}$ & $85 \mathrm{a}$ & \\
\hline \multicolumn{5}{|c|}{ Velocidade de germinação $\left(\right.$ dias $\left.^{-1}\right)$} \\
\hline Polietileno & $0,067 \mathrm{Ac}$ & $0,389 \mathrm{Ba}$ & $0,364 \mathrm{Bb}$ & 0,273 \\
\hline Papel & $0,059 \mathrm{Ab}$ & $0,384 \mathrm{Ba}$ & $0,380 \mathrm{ABa}$ & 0,274 \\
\hline Lata & $0,060 \mathrm{Ac}$ & $0,413 \mathrm{Aa}$ & $0,386 \mathrm{Ab}$ & 0,286 \\
\hline Média & 0,062 & 0,396 & 0,377 & \\
\hline \multicolumn{5}{|c|}{ Tabebuia impetiginosa } \\
\hline \multicolumn{5}{|c|}{ Germinação (\%) } \\
\hline Polietileno & $5 \mathrm{Bb}$ & $78 \mathrm{Ba}$ & $81 \mathrm{Aa}$ & 55 \\
\hline Papel & $1 \mathrm{Bb}$ & $80 \mathrm{ABa}$ & $81 \mathrm{Aa}$ & 54 \\
\hline Lata & $13 \mathrm{Ab}$ & $85 \mathrm{Aa}$ & $84 \mathrm{Aa}$ & 61 \\
\hline Média & 6 & 81 & 82 & \\
\hline \multicolumn{5}{|c|}{ Velocidade de germinação $\left(\operatorname{dias}^{-1}\right)$} \\
\hline Polietileno & $0,039 \mathrm{Bb}$ & $0,225 \mathrm{Aa}$ & $0,221 \mathrm{Aa}$ & 0,162 \\
\hline Papel & $0,026 \mathrm{Bb}$ & $0,226 \mathrm{Aa}$ & $0,236 \mathrm{Aa}$ & 0,163 \\
\hline Lata & $0,071 \mathrm{Ab}$ & $0,233 \mathrm{Aa}$ & $0,236 \mathrm{Aa}$ & 0,180 \\
\hline Média & 0,045 & 0,228 & 0,231 & \\
\hline
\end{tabular}

Médias seguidas pela mesma letra maiúscula na coluna ou minúscula na linha, não diferem entre si pelo teste de Tukey a 5\% de probabilidade.

\section{CONCLUSÕES}

O acondicionamento em lata e manutenção em geladeira é uma condição adequada para o armazenamento de sementes de Tabebuia roseo-alba e de Tabebuia impetiginosa. Sementes de T. impetiginosa também podem ser conservadas embaladas em saco de polietileno, saco de papel Kraft ou lata, quando estocadas em câmara refrigerada.

Alterações no vigor de sementes dessas espécies são primeiramente identificadas pela redução da velocidade de germinação.

\section{REFERÊNCIAS}

AGUIAR, I.B. Conservação de sementes. In: SILVA,
A.; PIÑA-RODRIGUES, F.C.M.; FIGLIOLIA, M.B. (Coord.). Manual técnico de sementes florestais. São Paulo: Instituto Florestal, 1995. p. 33-44. (Série Registros, n. 14).

BANZATTO, D.A.; KRONKA, S.N. Experimentação agrícola. 2. ed. Jaboticabal: Funep, 1992. 247 p.

BARBEDO, C.J.; CICERO, S.M. Utilização do teste de condutividade elétrica para previsão do potencial germinativo de sementes de ingá. Scientia Agrícola, v.55, n.2, p.249259, 1998.

BERJAK, P. Unifying perspectives of some mechanisms basic to desiccation tolerance across life forms. Seed Science Research, v.16, n.1, p.1-15, 2006.

BISQUERRA，R.; SARRIERA，J.C.; MARTÍNEZ，F. 
Introdução à estatística: enfoque informático com o pacote estatístico SPSS. Porto Alegre: Artmed, 2004. 255 p.

BORBA FILHO, A.B.; PEREZ, S.C.J.G.A. Seleção de substratos para o teste de germinação de sementes de espécies do gênero Tabebuia (Bignoniaceae). In: ENCONTRO DE BIÓLOGOS DO CONSELHO REGIONAL DE BIOLOGIA, 14., 2003, Cuiabá. Resumos... Cuiabá: Conselho Regional de Biologia - 1 (SP, MT, MS), 2003. p.86-87.

BORGES, E.E.L.; RENA, A.B. Germinação de sementes. In: AGUIAR, I.B.; PIÑA-RODRIGUES, F.C.M.; FIGLIOLIA, M.B. (Coord.). Sementes florestais tropicais. Brasília, DF: ABRATES, 1993. p. 83-135.

BORGHETTI, F.; FERREIRA, A.G. Interpretação de resultados de germinação. In: FERREIRA, A.G.; BORGHETTI, F. (Org.). Germinação: do básico ao aplicado. Porto Alegre: Artmed, 2004. p.209-222.

BRASIL. Ministério da Agricultura e Reforma Agrária. Regras para análise de sementes. Brasília, DF: SNDA/ DNDV/CLAV, 1992. 365 p.

CABRAL, E.L.; BARBOSA, D.C.A.; SIMABUKURO, E.A. Armazenamento e germinação de sementes de Tabebuia aurea (Manso) Benth. \& Hook. F. Ex. S. Moore. Acta Botânica Brasílica, v.17, n.4, p. 609-617, 2003.

CARNEIRO, J.G.A.; AGUIAR, I.B. Armazenamento de sementes. In: AGUIAR, I.B.; PIÑA-RODRIGUES, F.C.M.; FIGLIOLIA, M.B. (Coord.). Sementes florestais tropicais. Brasília, DF: ABRATES, 1993. p. 333-350.

CARVALHO, N.M.; NAKAGAWA, J. Sementes: ciência, tecnologia e produção. 4. ed. Jaboticabal: Funep, 2000. 588 p.

DEGAN, P.; AGUIAR, I.B.; SADER, R; PINTO, L.R. Composição química, sanidade, secagem e germinação de sementes de ipê-branco (Tabebuia roseo-alba (Ridl.) Sand. - Bignoniaceae). Revista Brasileira de Horticultura Ornamental, v.3, n.1, p.41-47, 1997.

FIGLIOLIA, M.B.; PIÑA-RODRIGUES, F.C.M. Manejo de sementes de espécies arbóreas. São Paulo: Instituto Florestal, 1995. 59 p. (Série Registros, n. 15).

GEMAQUE, R.C.R.; DAVIDE, A.C.; SILVA, E.A.A.; FARIA, J.M.R. Efeito das secagens lenta e rápida em sementes de ipê-roxo (Tabebuia impetiginosa (Mart.) Standl.) Cerne, v.11, n.4, p.329-335, 2005.

KAGEYAMA, P.Y.; SANCHEZ, S.P.A.; FERRAZ, E.M.; SOUZA, L.M.C. Armazenamento de sementes de três espécies nativas (Tabebuia heptaphylla, Erytrhina verna e Chorisia speciosa). Revista do Instituto Florestal, v.4, pt.2, p.435-439, 1992.

LABOURIAU, L.G. A germinação de sementes. Washington: Secretaria Geral da OEA, 1983. 173 p.

LORENZI, H. Árvores brasileiras: manual de identificação e cultivo de plantas arbóreas nativas do Brasil. 3. ed. Nova Odessa: Instituto Plantarum, 2000. v. 1.

MARCHI, J.L.; CÍCERO, S.M. Procedimentos para a condução do teste de condutividade elétrica em sementes. Informativo ABRATES, v.12, n.1,2,3, p.20-27, 2002.

MARCOS FILHO, J. Testes de vigor: importância e utilização. In: KRZYZANOWSKI, F.C.; VIEIRA, R.D.; FRANÇA NETO, J.B. (Ed.). Vigor de sementes: conceitos e testes. Londrina: ABRATES, 1999. p.1.1-1.21.

MARCOS FILHO, J. Fisiologia de sementes de plantas cultivadas. Piracicaba: Fealq, 2005. 495 p.

MARQUES, M.A.; PAULA, R.C.; RODRIGUES, T.J.D. Adequação do teste de condutividade elétrica para determinar a qualidade fisiológica de sementes de jacarandá-dabahia (Dalbergia nigra (Vell.) Fr. All. ex Benth.). Revista Brasileira de Sementes, v.24, n.1, p.271-278, 2002.

MELLO, C.M.C.; EIRA, M.T.S. Conservação de sementes de ipês (Tabebuia spp.). Revista Árvore, v.19, n.4, p.427432, 1995.

PIÑA-RODRIGUES, F.C.M.; PIRATELLI, A.J. Aspectos ecológicos da produção de sementes. In: AGUIAR, I.B.; PIÑA-RODRIGUES, F.C.M.; FIGLIOLIA, M.B. (Coord.). Sementes florestais tropicais. Brasília, DF: ABRATES, 1993. p.47-82.

POTT, A.; POTT, V.J. Plantas do pantanal. Brasília: Embrapa, 1994. 320 p.

ROBERTS, E.H. Predicting the storage life of seeds. Seed Science and Technology, v.1, n.2, p.499-514, 1973.

SANTOS, S.R.G.; PAULA, R.C. Teste de condutividade elétrica para avaliação da qualidade fisiológica de sementes de Sebastiania commersoniana (Bail) Smith \& Dows Euphorbiaceae. Revista Brasileira de Sementes, v.27, n.2, p.136-145, 2005.

SCHMIDT, L. Guide to handling of tropical and subtropical forest seed. Denmark: Danida Forest Seed Centree, 2000. 511 p.

SILVA, A.; FIGLIOLIA, M.B.; AGUIAR, I.B.; PERECIN, D. Liofilização e armazenamento de sementes de ipêrosa (Tabebuia heterophylla (A.P. Candolle) Britton) Bignoniaceae. Revista Brasileira de Sementes, v.23, n.1, p.252-259, 2001. 
SOUZA, V.C.; BRUNO, R.L.A.; ANDRADE, L.A. Vigor de sementes armazenadas de ipê-amarelo Tabebuia serratifolia (Vahl.) Nich. Revista Árvore, v.29, n.6, p.833-841, 2005.
VIEIRA, R.D.; KRZYZANOWSKI, F.C. Teste de condutividade elétrica. In: KRZYZANOWSKI, F.C.; VIEIRA, R.D.; FRANÇA NETO, J.B. (Ed.). Vigor de sementes: conceitos e testes. Londrina: ABRATES, 1999. p.4.1-4.26. 